\title{
Inequities in maternal and child health outcomes and interventions in Ghana
}

Eyob Zere ${ }^{1 *}$, Joses M Kirigia ${ }^{2}$, Sambe Duale ${ }^{3}$ and James Akazili ${ }^{4}$

\begin{abstract}
Background: With the date for achieving the targets of the Millennium Development Goals (MDGs) approaching fast, there is a heightened concern about equity, as inequities hamper progress towards the MDGs. Equity-focused approaches have the potential to accelerate the progress towards achieving the health-related MDGs faster than the current pace in a more cost-effective and sustainable manner. Ghana's rate of progress towards MDGs 4 and 5 related to reducing child and maternal mortality respectively is less than what is required to achieve the targets. The objective of this paper is to examine the equity dimension of child and maternal health outcomes and interventions using Ghana as a case study.
\end{abstract}

Methods: Data from Ghana Demographic and Health Survey 2008 report is analyzed for inequities in selected maternal and child health outcomes and interventions using population-weighted, regression-based measures: slope index of inequality and relative index of inequality.

Results: No statistically significant inequities are observed in infant and under-five mortality, perinatal mortality, wasting and acute respiratory infection in children. However, stunting, underweight in under-five children, anaemia in children and women, childhood diarrhoea and underweight in women $(\mathrm{BMI}<18.5)$ show inequities that are to the disadvantage of the poorest. The rates significantly decrease among the wealthiest quintile as compared to the poorest. In contrast, overweight (BMI 25-29.9) and obesity (BMI $\geq 30$ ) among women reveals a different trend there are inequities in favour of the poorest. In other words, in Ghana overweight and obesity increase significantly among women in the wealthiest quintile compared to the poorest. With respect to interventions: treatment of diarrhoea in children, receiving all basic vaccines among children and sleeping under ITN (children and pregnant women) have no wealth-related gradient. Skilled care at birth, deliveries in a health facility (both public and private), caesarean section, use of modern contraceptives and intermittent preventive treatment for malaria during pregnancy all indicate gradients that are in favour of the wealthiest. The poorest use less of these interventions. Not unexpectedly, there is more use of home delivery among women of the poorest quintile.

Conclusion: Significant Inequities are observed in many of the selected child and maternal health outcomes and interventions. Failure to address these inequities vigorously is likely to lead to non-achievement of the MDG targets related to improving child and maternal health (MDGs 4 and 5). The government should therefore give due attention to tackling inequities in health outcomes and use of interventions by implementing equity-enhancing measure both within and outside the health sector in line with the principles of Primary Health Care and the recommendations of the WHO Commission on Social Determinants of Health.

\section{Background}

Barely four years from the target date of 2015 to achieve the Millennium Development Goals (MDGs), there a growing concern on how to accelerate progress to achieving these targets. There is also a heightened

\footnotetext{
* Correspondence: zeyob@yahoo.com

${ }^{1}$ Washington DC, USA

Full list of author information is available at the end of the article
}

concern about equity, as it undermines efforts for sustained improvements across all segments of society and hampers progress towards the MDGs $[1,2]$. The thrust for a greater focus on equity in human development is gathering momentum at the international level [3]. Equity-focused approach accelerates the progress towards achieving the health MDGs, specially MDGs 4 and 5 related to reducing child and maternal mortality

\section{Biomed Central}


respectively, faster than the current path in a more costeffective and sustainable manner [4]. The health MDGs referred to in this study, their targets and indicators are presented in Table 1[5].

In Africa, modest progress has been registered towards achieving MDGs 4 and 5. However, the rate of progress has been short of what is required to reach the targets. In sub-Saharan Africa, under-five mortality rate decreased from an average of 180 per 1,000 live births in 1990 to 129 per 1,000 live births in 2009 [6]. This translates to an average annual rate of reduction (AARR) of $1.7 \%$, which is far below the AARR of $4.3 \%$ required to achieve the MDG 4 target of reducing by two-thirds, between 1990 and 2015, the mortality rate in under-five children. In sub-Saharan Africa, Madagascar, Eritrea and Cape Verde registered under-five mortality AARR of 4.3\% or more between 1990 and 2009 [7], and are thus on track to achieve the MDG 4A target. The corresponding AARR for Ghana for the period 19902009 was $2.9 \%$ [7], and therefore the country is not on track to achieve MDG4A target. Progress in achieving the MDG 5 target of reducing the maternal mortality ratio (MMR) by three-quarters, between 1990 and 2015, has been slow. In sub-Saharan Africa, the maternal mortality ratio decreased from an average of 870 per 100,000 live births in 1990 to 640 per 100,000 in 2008 corresponding to an AARR of $1.7 \%$, which is also far below the required $5.5 \%$ to achieve the MDG 5A target of maternal mortality reduction. Although many countries in the region are making progress to achieving the target, only two countries - Equatorial Guinea and Eritrea- are on track. Ghana's AARR in maternal mortality ratio during the same period was 3.3\% [8].

Modern health interventions play a significant role in reducing childhood mortality in Africa and other developing countries [9]. There is ample evidence that MDG 4 can be achieved if countries in sub-Saharan Africa and other developing regions of the world target the biggest childhood killers in children - diarrhoea, malaria and pneumonia that account for more than half of underfive deaths. Scaling up of essential curative, preventive and promotive childhood interventions such as immunization, breast feeding, vitamin A supplementation and provision of safe drinking water are necessary to curb childhood morbidity and mortality [10]. Interventions such as focused antenatal care (four visits with a health care provider) and use of skilled attendants during child birth are cost-effective interventions to curb maternal morbidity and mortality.

Despite the modest progress observed, there are substantial inequities in maternal and child health services coverage and health outcomes within and between countries [11]. Current evidence indicates that poor people in both rich and poor countries bear a disproportionately higher burden of ill-health and death, but contrary to expectation have disproportionately less access to health services and interventions than those who are better off [6]. Evidence from various studies in sub-Saharan Africa attests to this [12].

Thus for practical reasons, it is important to examine the equity dimension of health outcomes and interventions in order to better target resources to those who have greater needs and achieve the national and global health targets. This paper, therefore, uses Ghana as case study to assess wealth-related inequalities in maternal and child health outcomes and interventions that are deemed as inequities. Following Whitehead's seminal definition, equity in health is the absence of systematic inequalities in health or in the major social determinants of health among people that have different positions in social hierarchy [13].

\section{Brief profile of Ghana}

Ghana is located on the West Coast of Africa about 750 $\mathrm{km}$ north of the equator on the Gulf of Guinea. It has a total land area of 238,305 square kilometers and is bordered on the north by Burkina Faso, on the west by Cote d'Ivoire and on the east by Togo [14]. The country

Table 1 Official indicators of Millenium Development Goals on maternal and child health

\begin{tabular}{|c|c|c|}
\hline $\begin{array}{l}\text { Millenium } \\
\text { Development Goal }\end{array}$ & Target & Indicator \\
\hline $\begin{array}{l}\text { MDG 4: reduce child } \\
\text { mortality }\end{array}$ & $\begin{array}{l}\text { Target 4A: reduce by two-thirds, between } 1990 \text { and 2015, the mortality } \\
\text { rate in children younger than } 5 \text { years }\end{array}$ & $\begin{array}{l}\text { Indicator 4.1: Mortality rate in children younger } \\
\text { than } 5 \text { years } \\
\text { Indicator } 4.2 \text { : Infant mortality rate } \\
\text { Indicator } 4.3 \text { : Proportion of } 1 \text { year-old children } \\
\text { immunized against measles }\end{array}$ \\
\hline $\begin{array}{l}\text { MDG 5: Improve } \\
\text { maternal health }\end{array}$ & $\begin{array}{l}\text { Target 5A: reduce by three-quarters, between } 1990 \text { and 2015, the } \\
\text { maternal mortality ratio } \\
\text { Target 5B: Achieve by 2015, universal access to reproductive health }\end{array}$ & $\begin{array}{l}\text { Indicator 5.1: maternal mortality ratio } \\
\text { Indicator 5.2: proportion of births attended by } \\
\text { skilled health personnel } \\
\text { Indicator 5.3: contraceptive prevalence rate } \\
\text { Indicator 5.4: Adolescent birth rate } \\
\text { Indicator 5.5: antenatal care coverage (at least } \\
\text { one visit and at least } 4 \text { visits } \\
\text { Indicator 5.6: unmet need for family planning }\end{array}$ \\
\hline
\end{tabular}


is divided into 10 administrative regions and over 140 districts [15].

Ghana's population was estimated at 24 million in the 2010 Population and Housing Census. The population structure is typical of a developing country with about half of the total population below 15 years of age. Women in Ghana have an average of 4.0 children. The average number of children per woman ranges from 3.1 in urban areas to 4.9 in rural areas. Ghana is a lowincome country. The gross national income (GNI) per capita in 2009 was US\$ 700 [16].

The burden of disease in Ghana has not changed significantly for decades. Communicable diseases account for about two-thirds of outpatient visits across the nation. Malaria is the main cause of outpatient morbidity. National HIV prevalence increased from 1.7 per cent in 2008 to 1.9 in 2009. The burden of non-communicable diseases such as cardiovascular disorders, diabetes and cancers is emerging as a major challenge to service delivery and a threat to health and national productivity. Similarly, mental health and neurological disorders are also on the increase while trauma and other injuries are significant among outpatients [17].

Maternal mortality continues to be a significant public health challenge despite the increase in antenatal service delivery. Though antenatal care coverage has been sustained at a high level of about $85 \%$, deliveries by skilled personnel have declined from $44.5 \%$ in 2006 to $34.9 \%$ in 2007. Maternal mortality ratio has increased from 187.2 / 100,000 to $229.9 / 100,000$ live births respectively.

Ghana Health Service is organized at three main levels, national, regional and district. Payment mechanism for health care is a combination of health insurance and out-of-pocket payment.

\section{Methods}

\section{Data sources}

Data is extracted from Ghana demographic and health survey (GDHS) of 2008 report. The 2008 DHS was a nationally representative survey of 11,778 households comprising 4,916 women in the age group 15 to 49 years and 4,568 men aged 15-59 years. The survey employed a two-stage sampling based on the 2000 Population and Housing Census [18].

\section{Variables and definitions \\ Maternal and child health outcomes}

The health outcomes included in this study are defined in GDHS 2008 as indicated in Table 2[18].

\section{Maternal and child health interventions}

The interventions included in this study are defined in GDHS 2008 as indicated in Table 3[18].

\section{Analytical methods}

Measurement of inequities The measurement of inequities in maternal and child health outcomes and access to health care interventions entails three steps [19]: (i) identification of the health outcome or intervention whose distribution is to be measured; (ii) classification of the population into different strata by a selected equity stratifier; and (iii) measuring the degree of inequality.

The variables of interest, that is the maternal and child health outcomes and interventions are listed in Tables 2 and 3. In the Demographic and Health Surveys,

Table 2 Maternal and child health outcomes included in the study and their definitions

\begin{tabular}{|c|c|}
\hline Health outcome & Definition/measurement \\
\hline Infant mortality rate (IMR) & Probability of dying between birth and exactly age 1 \\
\hline Under-five mortality rate (U5MR) & Probability of dying between birth and exact age five \\
\hline Perinatal mortality rate & $\begin{array}{l}\text { Includes pregnancy losses of at least seven months gestation (stillbirths) and deaths among live births that } \\
\text { occurred within the first seven days of life (early neonatal deaths) }\end{array}$ \\
\hline Stunting & $\begin{array}{l}\text { Height-for-age of under-five children below minus two standard deviations of the WHO Child Growth Standards } \\
\text { median. }\end{array}$ \\
\hline Underweight & $\begin{array}{l}\text { Weight-for-age of under-five children below minus two standard deviations of the WHO Child Growth Standards } \\
\text { median. }\end{array}$ \\
\hline Wasting & $\begin{array}{l}\text { Weight-for-height of under-five children below minus two standard deviations of the WHO Child Growth } \\
\text { Standards median. }\end{array}$ \\
\hline Anaemia in children 6-59 years & Haemoglobin concentration below $11 \mathrm{~g} / \mathrm{dL}$ \\
\hline $\begin{array}{l}\text { Acute respiratory infection (ARI) in } \\
\text { children }\end{array}$ & Cough accompanied by short, rapid breathing in the two weeks preceding the survey \\
\hline Diarrhoea in children & $\begin{array}{l}\text { Mothers asked whether any of their children under five years of age had diarrhoea during the two weeks } \\
\text { preceding the survey }\end{array}$ \\
\hline $\begin{array}{l}\text { Nutritional status of women age } \\
15-49 \text { years }\end{array}$ & $\begin{array}{l}\text { Defined as weight in Kilograms divided by height squared in metres ( } \mathrm{Kg} / \mathrm{m}^{2)} \text { (Body Mass Index - BMI). A BMI of } \\
<18.5 \text { was regarded as thin, 18.5-24.9 normal, } 25-29.9 \text { overweight, and } \geq 30 \text { obese. }\end{array}$ \\
\hline $\begin{array}{l}\text { Anaemia in women age } 15-49 \\
\text { years }\end{array}$ & Haemoglobin concentration below $11 \mathrm{~g} / \mathrm{dL}$ in pregnant women and below $19 \mathrm{~g} / \mathrm{dL}$ in non-pregnant women \\
\hline
\end{tabular}


Table 3 Maternal and child health interventions included in the study and their definitions

\begin{tabular}{|c|c|}
\hline Intervention & Definition/measurement \\
\hline Child immunization & $\begin{array}{l}\text { A child is considered fully vaccinated when he/she gets one dose each of BCG and measles, three doses } \\
\text { each of polio vaccine and DPT }\end{array}$ \\
\hline Treatment of diarrhoea in children & $\begin{array}{l}\text { Percentage of children under-five with diarrhoea in the two weeks preceding the survey for whom advice or } \\
\text { treatment was sought from a health facility or provider }\end{array}$ \\
\hline Treatment of fever in children & $\begin{array}{l}\text { Percentage of children under-five with fever in the two weeks preceding the survey for whom advice or } \\
\text { treatment was sought from a health facility or provider }\end{array}$ \\
\hline Skilled birth attendance & $\begin{array}{l}\text { Percentage of births delivered by skilled providers that include doctor, nurse, midwife, auxiliary midwife and } \\
\text { community health officer }\end{array}$ \\
\hline Delivery at health facility & Percentage of births delivered in public and private sector health facilities \\
\hline Delivery at public facility & Percentage of births delivered in public sector health facilities \\
\hline Home delivery & Percentage of births delivered at home \\
\hline $\begin{array}{l}\text { Current use of modern contraceptive } \\
\text { method }\end{array}$ & $\begin{array}{l}\text { Percentage of currently married women age } 15-49 \text { who use modern contraceptive methods that include } \\
\text { female sterilization, temporary female methods (pill, IUD, injectable, implants, female condom, diaphragm, } \\
\text { foam/jelly and lactational amenorrhoea method) and male condom }\end{array}$ \\
\hline Caesarean section & Percentage of live births in the five years preceding the survey delivered by Caesarean section \\
\hline ITN use, child & Percentage of children in all households who slept under ITN the past night \\
\hline ITN use, pregnant woman & Percentage of pregnant women age 15-49 who slept under ITN past night \\
\hline $\begin{array}{l}\text { Intermittent preventive treatment, } \\
\text { pregnant woman }\end{array}$ & $\begin{array}{l}\text { Percentage of women age } 15-49 \text { years who had a live birth in the two years preceding the survey who } \\
\text { received at least } 2 \text { doses of sulphadoxine-pyrimethamine (SP), at least one during antenatal care visit }\end{array}$ \\
\hline
\end{tabular}

the socio-economic stratifier used is household wealth, which is derived from the household ownership of assets such as television, car etc. and dwelling characteristics such as flooring material and source of drinking water. In this study, we have used wealth quintiles that are provided in the DHS report. In this study, we have used wealth quintiles that are provided in the DHS report. Each asset was assigned a weight (factor score) generated through principal components analysis, and the resulting asset scores were standardised in relation to a normal distribution with a mean of zero and standard deviation of one. Each household was then assigned a score for each asset, and the scores were summed for each household; individuals were ranked according to the total score of the household in which they resided. The sample was then divided into quintiles from one (lowest) to five (highest). A single asset index was developed for the whole sample; separate indices were not prepared for the urban and rural populations [18].

To date, various measures have been used in the measurement of inequities in health and health care. Of the available measures only the slope index of inequality (SII), the relative index of inequality (RII) and the concentration index have the following desirable characteristics: (i) they reflect the socio-economic dimension of health inequalities; (ii) they reflect the experience of the entire population rather than only two groups such as wealth quintiles one and five and (iii) they are sensitive to changes in the distribution of the population across socio-economic groups [20].

In this study, the presence or absence of inequities is measured using population-weighted, regression-based measures: SII and RII. These measures are selected for this analysis because of their ease of interpretation. The SII and RII are based on the socio-economic dimension to inequalities in health and are weighted by the social group proportions [20,21]. The SII is a measure of absolute effect, while the RII measures relative effect. The SII and RII are interpreted as the effect on health or utilization of health care intervention of moving from the lowest to the highest socio-economic group, which is from wealth quintile 1 to wealth quintile 5 .

To compute the SII, social groups (wealth quintiles) are ranked from lowest to highest. The population in each wealth quintile covers a range in the distribution of the population and is given a score based on the midpoint of its range in the cumulative distribution in the population. The SII is the linear regression coefficient (slope of the regression line) showing the relationship between a group's (wealth quintile in this case) health and its relative socio-economic rank. In other words:

$$
y_{i}=\beta_{0}+\beta_{1} x_{i}+\varepsilon
$$

Where:

$y_{i}$ is the value of the health variable of wealth quintile $i$;

$x_{i}$ is the relative rank of wealth quintile $i$;

$\beta_{0}$ is the constant or intercept term, which captures the value of $y$ when $x$ equals zero;

$\beta_{i}$ is the slope coefficient (or parameter), and it indicates the amount the $\mathrm{y}$ will change when $\mathrm{x}$ changes by one unit; and

$\varepsilon$ is the stochastic error (or disturbance) term that captures the variation in $y$ that cannot be explained by the included $x_{i}$. 
The coefficient $\beta_{I}$ represents the SII. The relative index of inequality is derived from the SII as follows:

$$
R I I=\frac{S I I}{\mu}=\frac{\beta_{1}}{\mu}
$$

where, $\mu$ is the population average of the specific health variable.

However, because we are making use of grouped data, the error term of the regression equation is heteroskedastic making the Ordinary Least Squares (OLS) estimates inefficient. To avoid this problem, the SII is therefore estimated using Weighted Least Squares (WLS) [20]. This can be done by running OLS regression on the following transformed equation:

$$
y_{i} \sqrt{n_{i}}=\beta_{0} \sqrt{n_{i}}+\beta_{1} x_{i} \sqrt{n_{i}}+\varepsilon_{i}
$$

Where, $n_{i}$ is the size of wealth quintile " $i$ ", that is the number of individuals in each wealth quintile. It has to be noted that there is no constant term in Equation (3).

SII and RII avoid the defects of the range measures such as rate difference between the wealthiest and poorest quintiles or rate ratio of these two extreme quintiles. They reflect the experience of the entire population as opposed to extreme groups such as wealth quintiles 1 and 5 and are sensitive to the distribution of the population across socio-economic groups (wealth quintiles). The disadvantage of the SII/RII is that it can only be applied to socio-economic variables that can be ordered hierarchically. Besides, linearity is assumed in the regression model; non-linearity would lead to bias in the magnitude of the index.

Data was analyzed using STATA 10 statistical software.

\begin{tabular}{ll}
$\begin{array}{l}\text { Table } 4 \text { Ghana selected maternal and child health } \\
\text { indicators }\end{array}$ \\
\hline Indicator & Value \\
\hline IMR per 1000 live births & 50 \\
U5MR per 1000 live births & 80 \\
Perinatal mortality rate per 1000 live births & 39 \\
Stunting (\%) & 37.8 \\
Underweight (\%) & 17 \\
Wasting (\%) & 10.7 \\
Anaemia among children 6-59 months (\%) & 77.9 \\
Acute respiratory infection (\%) & 5.5 \\
Diarrhoea (\%) & 19.8 \\
Body mass index < 18.5 (thin) (\%) & 8.6 \\
Body mass index, 25-29.9 (overweight) (\%) & 20.7 \\
Body mass index $\geq 30$ (obese) (\%) & 9.3 \\
Anaemia among women age 15-49 years (\%) & 58.7 \\
\hline
\end{tabular}

\section{Results}

\section{Descriptive statistics}

Table 4 depicts the values of the selected maternal and child health outcome indicators according to the GDHS 2008. Distribution of all indicators in this study by wealth quintile is provided in Additional file 1: Annex 1.

The infant and under-five mortality rates are relatively better when compared to averages of sub-Saharan Africa, which in 2009 were 81 per 1,000 live births and 129 per 1,000 live births respectively. However, they still remain high. The level of childhood malnutrition is very high and of public health significance. According to the World Health Organization's prevalence cut-off values for public health significance [22], the level of malnutrition in Ghana is classified as very high prevalence of stunting and high prevalence of underweight and wasting. It is also noted that the prevalence of overweight and obesity combined is more than three times the prevalence of thinness (or underweight) among women in the 15-49 years age group. It is also observed that more than a third of the Ghanaian women are thin, overweight or underweight, implying that only about $60 \%$ have a normal body weight. The table further indicates that the prevalence of anaemia among children and women is alarming and a public health problem. Almost 4 out of 5 children 6-59 months of age and more than half of women in the 15-49 years age group were found to be anaemic (Table 4).

Analysis of the BMI by household wealth quintile gives a mixed picture on the prevalence of malnutrition among women (Figure 1). The prevalence of underweight (thin) is high among the poorest quintiles and decreases with the improvement of the socio-economic status of the household. However, underweight and obesity are more prevalent among women in the top wealth quintile.

Table 5 depicts the values of selected maternal and child health intervention indicators according to the GDHS 2008. Coverage of vital maternal and child health services is critically low except for childhood immunization and caesarean delivery.

The coverage rates depicted in Table 5 would give a comprehensive view of the situation if the distributional dimension is included. As an example, the case of maternal health interventions is depicted in Figure 2. The figure indicates that there is no difference in the use of antenatal services among pregnant women from different socio-economic backgrounds. However, all the other indicators favour women from the richer wealth quintiles. Home delivery is mainly practiced by poor women and declines sharply with improvements in the economic status of the woman. The population average rate of Caesarean delivery is about 6.9\%; disaggregation 


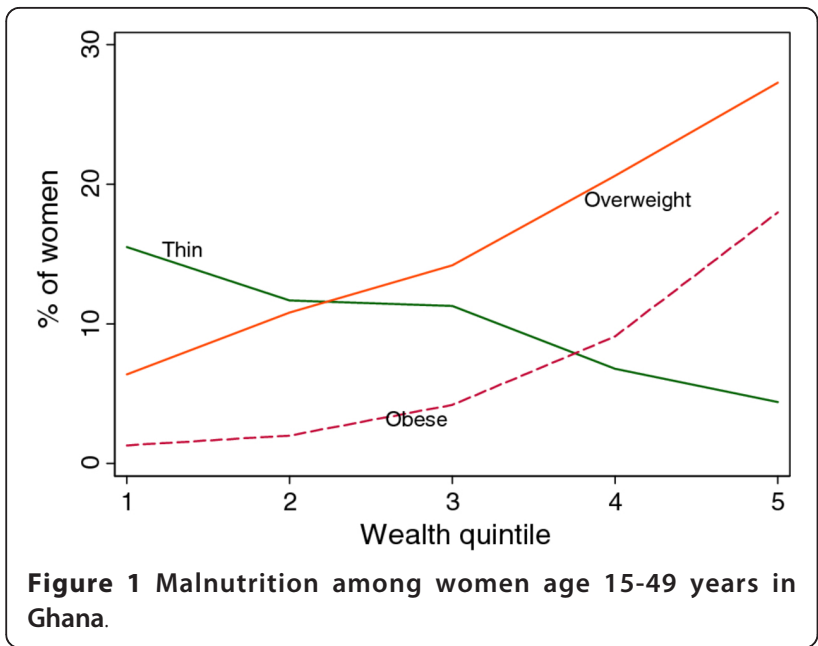

of the rate by wealth quintile shows that it is only $1.3 \%$ among the bottom $20 \%$ compared to $15 \%$ among the wealthiest $20 \%$.

\section{Inequities in maternal and child health outcomes}

Inequities in maternal and child health outcomes exist when there are inequalities in each of the selected indicators that are systematically related to household wealth derived from asset indices. Table 6 presents the SII and RII for the health outcomes.

From Table 6 it is observed that the SII and RII for the indicators IMR, U5MR, perinatal mortality rate, wasting and ARI in children are not statistically significant implying that there are no inequities in these health outcomes. The prevalence of Stunting significantly decreases by 25 percentage points as we move from wealth quintile 1 to 5 . In relative measures this implies that as one moves from the bottom wealth quintile to the top, the prevalence of stunting decreases by $90 \%$ $(\mathrm{RII}=-0.90)$. Similarly, anaemia in children and women, childhood diarrhoea, and underweight (thinness) in women 15-49 years of age demonstrate inequities favouring the wealthiest, as the respective rates decrease significantly among those in the top wealth quintile. A point worth of note is that, while underweight in women decreases by $142 \%$ (RII $=-1.42)$ in women in the wealthiest quintile as compared with those in the bottom wealth quintile, overweight and obesity demonstrate a different trend. Overweight and obesity increase by $118 \%(\mathrm{RII}=1.18)$ and $247 \%(\mathrm{RII}=2.47)$ respectively as we move from the bottom quintile to the top. The prevalence rates of overweight and obesity are significantly higher among those who are in a better economic position.

\section{Inequities in maternal and child health interventions}

The analysis shows that treatment of diarrhoea in children, children receiving all basic vaccines and sleeping under ITN (both children and pregnant women) have no wealth-related gradient.

Table 7 presents the SII and RII values of the selected interventions. Skilled attendance at birth, which is an important intervention for the achievement of the MDG 5 target of curbing maternal mortality, is observed to increase by $150 \%$ among women in the highest wealth quintile as compared to those in the lower. Similarly deliveries in public or private sector health facility increase among women in the highest socio-economic group by the same magnitude. In contrast, home delivery decreases by about $200 \%$ when we move from those in the lowest wealth quintile to those in the top. Thus, home delivery is practiced more by the poorest. The rate of caesarean section and the use of modern contraceptive methods increase by more than $200 \%$ and $72 \%$ respectively among the wealthiest women. Furthermore intermittent preventive treatment of malaria during pregnancy manifested an increase by $55 \%$ among those

Table 5 Ghana selected maternal and child health intervention indicators

\begin{tabular}{ll}
\hline Indicator & Value \\
\hline Children 12-23 months age who received all basic vaccinations (\%) & 79 \\
Children under-five who slept under an ITN (\%) & 28.2 \\
Children under-five with diarrhoea for whom advice or treatment was sought from a health facility or provider (\%) & 41 \\
Births assisted by a skilled provider (\%) & 58.7 \\
Delivery in a health facility (\%) & 57.1 \\
Delivery in a public sector health facility & 48.4 \\
Delivery in a private sector health facility & 8.7 \\
Home delivery (\%) & 42 \\
Delivery by Caesarean section & 6.9 \\
Currently married women age 15-49 who use modern contraceptive methods (\%) & 16.6 \\
Pregnant women who slept under an ITN (\%) & 19.9 \\
Intermittent preventive treatment (IPT) among women during pregnancy (\%) & 43.7 \\
\hline
\end{tabular}




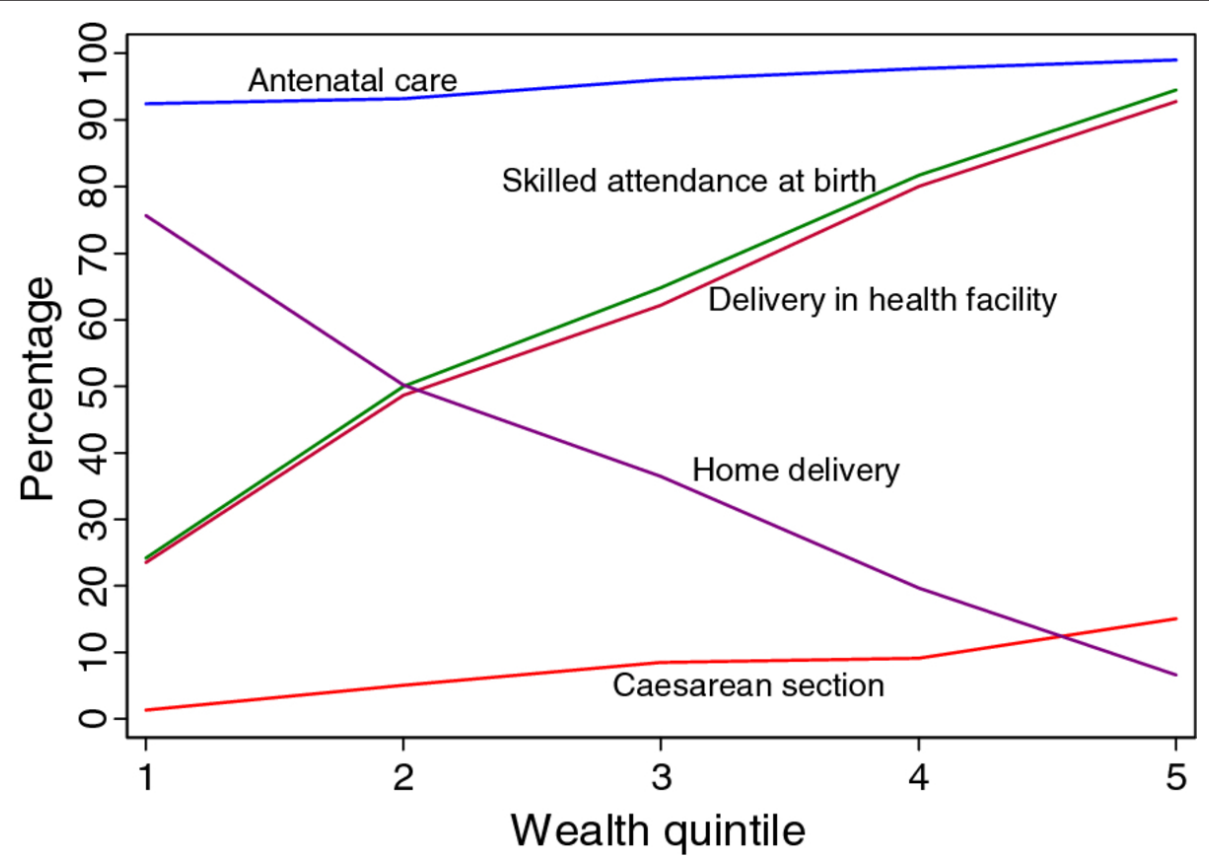

Figure 2 Coverage rates of selected maternal health interventions by household wealth quintile.

in the wealthiest quintile. Use of ITNs both among children and pregnant women did not show any socio-economic inequalities.

\section{Discussion and conclusion}

This study attempts to examine socio-economic inequalities in maternal and child health outcomes and interventions in Ghana using population weighted, regression-based measures of slope and relative index of inequality. Assessing these socio-economic inequalities, which in this case are referred to us inequities, is very

Table 6 Slope and relative indices of inequality for selected maternal and child health outcomes

\begin{tabular}{ccccccc}
\hline \multirow{2}{*}{ Indicator } & \multicolumn{3}{c}{$95 \% \mathrm{Cl}^{\#}$} & \multicolumn{3}{c}{$95 \% \mathrm{Cl}$} \\
& SII & Lower & Upper & RII & Lower & Upper \\
\hline IMR & -11.9 & -71.9 & 48.2 & 0.24 & -1.44 & 0.96 \\
U5MR & -46.5 & -117 & 24.1 & -0.58 & -1.46 & 0.30 \\
Perinatal mortality rate & 17.2 & -52.4 & 86.8 & 0.44 & -1.34 & 2.23 \\
Stunting & $-25.3^{*}$ & -39.5 & -11.1 & -0.90 & -1.04 & -0.29 \\
Underweight & $-15.4^{*}$ & -22.5 & -8.3 & -1.12 & -1.32 & -0.49 \\
Wasting & -4.6 & -10.9 & 1.8 & -0.54 & -1.28 & 0.21 \\
Anaemia in children & $-32^{*}$ & -52.7 & -11.3 & -0.41 & -0.68 & -0.14 \\
ARI in children & -1.8 & -10.2 & 6.7 & -0.33 & -1.85 & 1.23 \\
Diarrhoea in children & $-16.4^{*}$ & -27.3 & -5.6 & -0.82 & -1.38 & -0.28 \\
BMI < 18.5 (thin) & $-12.2^{*}$ & -21.9 & -2.5 & -1.42 & -2.55 & -0.29 \\
BMI 25-29.9 (overweight) & $24.5^{*}$ & 5.2 & 44.6 & 1.18 & 0.25 & 2.15 \\
BMI $\geq 30$ (obese) & $23.0^{*}$ & 10.7 & 35.3 & 2.47 & 1.15 & 3.38 \\
Anaemia in women & $-9.9^{*}$ & -18.4 & -1.3 & -0.17 & -0.31 & -0.02 \\
\hline \# confidence interval; * $P<0.05$ & & & & &
\end{tabular}

important for evidence-based decision-making and targeting scarce public resources to those with more need. Achieving the relevant health-related MDG targets becomes difficult in the presence of inequities in health and health care that disadvantage the poor, since it is among the poorest groups that the MDG indicators are not good and there is a significant potential for improvement in these groups [2].

The selected maternal and child health outcomes indicate that a challenging task lies ahead to improve the health status of women and children in Ghana, although some of the indicators appear relatively better compared to average figures for countries in sub-Saharan Africa. The high rates of childhood mortality and malnutrition among children and women are of great concern if the country is to accelerate progress towards achieving the MDGs related to maternal and child health. Anaemia is a severe public health problem in Ghana, as it exceeds the $40 \%$ cut-off mark for the classification of public health significance of anaemia in populations [23].

The overall coverage levels of the selected maternal and child health interventions are still low with the exception of immunization coverage and Caesarean delivery. It should, however, be noted that these average figures mask the reality. For example, while the population average rate of Caesarean delivery is about 6.9\%; disaggregation of the rate by wealth quintile shows that the rate among the wealthiest $20 \%$ is 14 times more than the rate among the poorest $20 \%$ (15\% vs. $1.3 \%)$. Although there is a debate, a population-based 
Table 7 Slope and relative indices of inequality for selected maternal and child health interventions

\begin{tabular}{|c|c|c|c|c|c|c|}
\hline \multirow[t]{2}{*}{ Indicator } & \multicolumn{4}{|c|}{$95 \% \mathrm{Cl}$} & \multicolumn{2}{|c|}{$95 \% \mathrm{Cl}$} \\
\hline & SII & Lower & Upper & RII & Lower & Upper \\
\hline Treatment of diarrhoea in children & 3.6 & -11.0 & 18.3 & 0.09 & -0.27 & 0.45 \\
\hline Received all basic vaccines - children & 13.9 & -3.9 & 31.7 & 0.18 & -0.05 & 0.40 \\
\hline Skilled attendance at birth & $87.5^{*}$ & 75.6 & 99.5 & 1.5 & 1.29 & 1.70 \\
\hline Delivery in health facility & $86.1^{*}$ & 74.2 & 97.9 & 1.5 & 1.30 & 1.71 \\
\hline Delivery in public sector health facility & $65.4^{*}$ & 47.4 & 83.3 & 1.4 & 0.98 & 1.72 \\
\hline Delivery in private sector health facility & $20.6^{*}$ & 7.3 & 33.8 & 2.4 & 0.84 & 3.89 \\
\hline Home delivery & $-85.5^{*}$ & -97.8 & -73.2 & -2.0 & -2.33 & -1.47 \\
\hline Caesarean section & $15.2^{*}$ & 8.7 & 21.8 & 2.20 & 1.26 & 3.16 \\
\hline Use of modern contraceptive methods & $11.9^{*}$ & 11.3 & 16.5 & 0.72 & 0.68 & 0.99 \\
\hline Child slept under ITN & -3.1 & -12.3 & 6.1 & -0.11 & -0.43 & 0.22 \\
\hline Pregnant woman slept under ITN & -16.2 & -45 & 12.1 & -0.81 & -2.26 & 0.61 \\
\hline IPT during pregnancy & $23.9^{*}$ & 1.5 & 46.4 & 0.55 & 0.03 & 1.06 \\
\hline
\end{tabular}

${ }^{* P}<0.05$

Caesarean section rate of $5-15 \%$ has been considered as the acceptable level to ensure the best outcomes for mothers and children [24]. The proportion of deliveries by Caesarean section in a geographical area is a measure of access to and use of obstetric emergency care for averting maternal and neonatal deaths [19]. Therefore, there is under-provision of Caesarean section to the poorest segment of society, which poses a serious challenge to curbing maternal mortality. This impedes the achievement of MDG 5.

The slope and relative indices of inequality reveal the existence of statistically significant gradients in the following health outcome measures: stunting, underweight, anaemia and diarrhoea in under-five children; and, underweight $/$ thin $(\mathrm{BMI}<18.5)$, overweight $(\mathrm{BMI}=25$ $29.9)$, obese (BMI $\geq 30$ ) and anaemia in women in the age group 15-49 years. With the exception of overweight and obesity in women 15-49 age, all other indicators show a pro-wealthy inequity. This implies that the rates of these health outcome indicators decline significantly as one moves from the poorest wealth quintile to the wealthiest quintile. In contrast, the childhood mortality indicators - IMR, U5MR and perinatal mortality rate and wasting in under-five children do not exhibit wealth related gradients that may be labeled as inequities.

The nutritional status of under-five children is one of the indicators of household well-being and determinants of child survival [25]. The world Health Organization recommends it as one of the measures of health status to assess equity in health [26]. Besides being an important cause of under-five mortality $[27,28]$, childhood malnutrition may adversely affect a child's intellectual development and consequently, health and productivity in later life $[29,30]$. Wealth-related inequities in stunting (chronic malnutrition) and underweight in favour of the top wealth quintile clearly demonstrate the well- established link with socio-economic deprivation [31]. Hence, addressing inequities in stunting and underweight will entail initiating and implementing a multisectoral action and tackling the broader social determinants of malnutrition in line with the recommendations of the WHO Commission on Social Determinants of Health [32].

The overall prevalence of anaemia among under-five children is consistent of settings where malaria is endemic [33]. Anaemia affects the poorest of society disproportionately [22]. This is attested to by the finding of this study of the existence of inequities in anaemia prevalence in favour of children from wealthier segment of society. This inequity will adversely affect progress towards MDG 4, as anaemia is associated with an increased risk of child mortality [22].

The wealth-related gradient in childhood diarrhoea that is to the disadvantage of children from the poorest wealth quintile is not surprising. diarrhoea is the second main cause of death among children under-five globally [34]. It is therefore a priority to control diarrhoea in children in Ghana in order to accelerate progress towards the MDG 4 target.

Inequities in health outcomes (including diarrhoea) that are to the disadvantage of the poorest children result from increase exposure to disease risk factors; low coverage of preventive interventions and limited access to curative services $[12,35]$. These problems require interventions both within and outside the health sector that the stewards of health in Ghana have to address simultaneously in order to expedite progress towards the MDGs in a sustainable manner.

The BMI indicator suggests the co-existence of overweight and obesity on the one hand and underweight on the other among women 15-49 years of age. While there are inequities in favour of the rich in the 
prevalence of underweight (thin), overweight and obesity manifest inequities in the opposite direction - to the advantage of the poor. Underweight significantly decreases in the wealthiest quintile of the population compared to those in the bottom $20 \%$. However, overweight and obesity increase in the wealthiest quintile compared to the poorest $20 \%$. Ghana, like other developing countries may be experiencing the double burden of malnutrition. Abnormal BMI has an adverse effect on pregnancy outcomes [36] and is likely to impede progress towards achieving the MDGs on maternal and child health. It is therefore essential to put appropriate measures that help women to maintain normal BMI.

Anaemia among women likewise manifests prowealthy inequities. However, it should be noted that even among the wealthiest quintile, the rate is in the range that is labeled as severe public health problem. Anaemia poses an increased risk for maternal and child mortality [22] and is likely to directly thwart efforts to achieving the MDGs 4 and 5 targets. Although the poorest have to be targeted with preventive and curative interventions, given the magnitude of the problem, it is vital to also implement measures aimed at universal coverage with interventions against anaemia.

The results indicate that the following interventions do not manifest wealth-related gradients: treatment of diarrhoea in children, childhood vaccines, sleeping under ITN (child and pregnant woman). Skilled attendance at birth, place of delivery (health facility, public health facility, private health facility) and Caesarean delivery increase significantly among the wealthiest compared to the poor. It is interesting to note that even the publicly-funded child delivery services are used more by the rich than the poor, reinforcing the assertion that government health spending in Africa benefits the richest of society more than the poorest [37]. It is evident that access of the poor to emergency obstetric care services has to be increased in order to improve maternal health conditions. However, this should not only be limited to increase in the supply of emergency obstetric care. Demand side factors (e.g. individual, household and community level characteristics) should also be examined in order to address any obstacles to utilizing these services by the poorest women.

Not unexpectedly, home delivery significantly decreases as we move from the poorest wealth quintile to the highest. There is an urgent need to reverse this situation so that more women from the poorest of society will give birth at health facilities under the supervision of skilled birth attendants. This will go a long way in bridging inequities and accelerating the progress towards achieving the maternal mortality reduction target of MDG 5.
The fact that intermittent preventive treatment for malaria during pregnancy has a pro-rich inequity may possibly raise a question about the responsiveness of the health system. For example, the Ghana DHS 2008 shows that while $80 \%$ of women in the wealthiest quintile are informed of signs of complications of pregnancy, only $55 \%$ of those in the poorest quintile are provided with the same information. Thus, socio-economic status seems to affect the quality of care provided to pregnant women.

In summary, pro-rich inequities in most of the maternal and child health interventions in Ghana are wide spread and need to be addressed vigorously in order to improve the health conditions of the poorest women and children and expedite progress towards achieving the MDGs related to maternal and child health in the few years left to the target date of the MDGs.

\section{Additional material}

Additional file 1: Annex 1. Distribution of indicators by wealth quintile.

\section{Acknowledgements}

The authors would like to thank colleagues who commented on earlier versions of the report. All errors of omission or commission are the sole responsibility of the authors. The manuscript contains the analysis and views of the authors only and does not represent the decisions or stated policies of the institutions that they work for.

\section{Author details}

${ }^{1}$ Washington DC, USA. ${ }^{2}$ World Health Organization, Regional Office for Africa, Brazzaville, Congo. ${ }^{3}$ Tulane University School of Public Health and Tropical Medicine, New Orleans, LA, USA. ${ }^{4}$ Navrongo Health Research Centre, Ghana Health Service, Navrongo, Ghana.

\section{Authors' contributions}

EZ designed the study, performed the analysis and drafted the report. JMK, SD and JA contributed to the write up and revision of the manuscript. All authors read and approved the final manuscript.

\section{Competing interests}

The authors declare that they have no competing interests.

Received: 26 August 2011 Accepted: 31 March 2012

Published: 31 March 2012

\section{References}

1. Overseas Development Institute: The MDG fundamentals: improving equity for development. ODI briefing paper. London; 2010.

2. Committee for Development Policy, United Nations: Implementing the Millennium Development Goals: Health inequality and the role of Global Health Partnership New York: United Nations; 2009.

3. United Nations Children's Fund: Progress for Children: achieving the MDGs with equity New York: UNICEF; 2010.

4. United Nations Children's Fund: Narrowing the gaps to meet the goals New York: UNICEF; 2010.

5. United Nations Statistics Division: Official list of MDG indicators [http://mdgs, un.org/unsd/mdg/Host.aspx?Content=Indicators/OfficialList.htm], accessed 1 February 2011

6. United Nations: The Millennium Development Goals Report 2011 New York: United Nations; 2009. 
7. United Nations Children's Fund: The State of the World's Children 2011: Adolescence - an age of opportunity New York: UNICEF; 2011.

8. WHO, UNICEF, UNFPA, World Bank: Trends in maternal mortality: 1990 to 2008 Geneva: WHO; 2010.

9. Mulholland EK, Smith L, Carneiro I, Becher H, Lehmann D: Equity and childsurvival strategies. Bull World Health Organ 2008, 86:399-407.

10. United Nations: The Millennium Development Goals Report 2010 New York: United Nations; 2010.

11. World Health Organization Regional Office for Africa: Health inequities in the African Region of the World Health Organization: Magnitudes, trends and sources Brazzaville: WHO/AFRO; 2010.

12. Zere $\mathrm{E}$, Moeti M, Kirigia J, Mwase T, Kataika E: Equity in health and healthcare in Malawi: analysis of trends. BMC Publ Health 2007, 7:78,

13. Whitehead $\mathrm{M}$ : The concepts and principles of equity in health. Int $J$ Health Serv 1992, 22:429-445.

14. Asante F, Aikins M: Does the NHIS cover the poor? Accra: Institute of Statistical Social \& Economic Research and School of Public Health at the University of Ghana; 2008.

15. Ghana Health Service: Annual Report Accra; Ghana Health Service; 2007.

16. World Bank: World Development Report 2011 - Conflict, security and development Washington DC: World Bank; 2011.

17. Ghana Statistical Service: Patterns and Trends of Poverty in Ghana 1991-2006 Accra; Ghana Statistical Service; 2007.

18. Ghana Statistical Service: Ghana Demographic and Health Survey 2008 Accra, Ghana and Claverton, USA; Ghana Statistical Service; 2009.

19. Zere $E$, Tumusiime P, Walker O, Kirigia J, Mwikisa C, Mbeeli T: Inequities in utilization of maternal health interventions in Namibia: Implications for progress towards MDG 5 targets. Int J Equity Health 2010, 9:16.

20. Wagstaff $A$, Paci $P$, Van Doorslaer $E$ : On the measurement of inequalities in health. Soc Sci Med 1991, 33(5):545-557.

21. Carr-Hill R, Chalmers-Dixon P: The Public Health Observatory Handbook of Health Inequalities Measurement. Oxford, UK; 2005.

22. World Health Organization: Nutrition Landscape Information System (NLIS) country profile indicators: interpretation guide Geneva: WHO; 2010.

23. World Health Organization, United Nations Children's Fund, United Nations University: Iron deficiency anaemia: Assessment, prevention and control - A guide for programme managers Geneva: WHO; 2001.

24. Dumont A, de Bernis L, Bouvier-Colle MH, Bréart G: Caesarean section rate for maternal indication in Sub-Saharan Africa: a systematic review. Lancet 2001, 358:1328-1334.

25. Thomas D, Strauss J, Henriques MH: Child survival, height for age and household characteristics in Brazil. J Dev Econ 1990, 33:197-234.

26. Braveman $\mathrm{P}$ : Monitoring equity in health: A policy-oriented approach in low- and middle-income countries. WHO/CHS/HSS/98.1, Equity Initiative Paper No. 3 Geneva: World Health Organization; 1998.

27. Pelletier DL, Frongillo EA, Schroeder DG, Habicht JP: The effects of malnutrition on child mortality in developing countries. Bull World Health Organ 1995, 73(4):443-448.

28. Svedberg P: Undernutrition in Sub-Saharan Africa: A critical assessment of the evidence, Working Paper No. 15 Helsinki: World Institute for Development Economics Research; 1987.

29. Cravioto J, Arrieta R: Nutrition, mental development and learning. In Human growth: A comprehensive treatise. Volume 3. Edited by: Falkner F, Tanner J. New York: Plenum Press; 1986, 2/e.

30. World Health Organization: Physical status: the use and interpretation of anthropometry. Technical Report Series No. 854.Geneva; 1995.

31. Zere E, McIntyre D: Inequities in under-five child malnutrition in South Africa. Int J Equity Health 2003, 2:7.

32. World Health Organization: Closing the gap in a generation: health equity through action on the social determinants of health. Final report of the Commission on Social determinants of Health Geneva: WHO; 2008.

33. Schellenberg D, Armstrong Schellenberg JRM, Mushi A, de Savigny D, Mgalula L, Mbuya C, Victora CG: The silent burden of anaemia in Tanzanian children: a community-based study. Bulletin World Health Organization 2003, 81(8):581-590.

34. United Nations Children's Fund, World Health Organization, Diarrhoea: Why children are still dying and what can be done New York: UNICEF; 2009.

35. In Equity, social determinants and public health programmes. Edited by: Blas E, Kurup AS. Geneva: World Health Organization; 2010:

36. Sahu MT, Agarwal A, Das V, Pandey A: Impact of maternal body mass index on obstetric outcome. J Obstet Gynaecol Res 2007, 33(5):655-659.
37. Castro-Leal F, Dayton J, Demery L, Mehra K: Public spending on health care in Africa: do the poor benefit? Bull World Health Organ 2000, 78:66-74.

\section{Pre-publication history}

The pre-publication history for this paper can be accessed here: http://www.biomedcentral.com/1471-2458/12/252/prepub

doi:10.1186/1471-2458-12-252

Cite this article as: Zere et al: Inequities in maternal and child health outcomes and interventions in Ghana. BMC Public Health 2012 12:252.

\section{Submit your next manuscript to BioMed Central and take full advantage of:}

- Convenient online submission

- Thorough peer review

- No space constraints or color figure charges

- Immediate publication on acceptance

- Inclusion in PubMed, CAS, Scopus and Google Scholar

- Research which is freely available for redistribution 